\title{
O dilema dA TOLdo METALMECÂNICA: CASO DE ENSINO
}

\author{
THE DILEMMA OF SHEET METALMECHANICAL: TEACHING CASE
}

Recebido em 27.04.2014. Aprovado em 03.12.2014 Avaliado pelo sistema double blind review

DOI: http://dx.doi.org/10.12712/rpca.v8i4.435

\section{Eliana Andréa Severo \\ elianasevero2@hotmail.com \\ Centro Federal de Educação Tecnológica Celso Suckow da Fonseca - Rio de Janeiro - RJ - Brasil}

\section{Julio Cesar Ferro de Guimarães}

juliocfguimaraes@yahoo.com.br

Universidade Potiguar - Natal - RN - Brasil

\section{Resumo}

O setor metalomecânico é um grande impactante ambiental, pois além de consumir recursos naturais, gera uma série de poluentes ambientais. Destaca-se que está cada vez mais evidente a questão ambiental e social, tanto no Brasil como na grande maioria dos países do ocidente. As estratégias ambientais propõe que novas tecnologias e ações sejam desenvolvidas no âmbito da economia ambiental, ecológica e social. A Toldo Metalmecânica Ltda é uma empresa que surgiu em virtude das habilidades e visão empreendedora do proprietário Rui Toldo. Após 33 anos atuando no mercado nacional o empresário necessitava abarcar novos mercados, pois estava se tornando impossível competir no mercado local e a empresa apresentava problemas ambientais. Neste sentido a empresa deveria se adequar o mais rápido possível, pois a pressão dos stakeholders influenciava a comercialização dos produtos. 0 objetivo desse caso de ensino é propor reflexões acerca das decisões e ações associadas à gestão ambiental e a responsabilidade social aplicada às empresas Metalmecânicas. Sua utilização está indicada em cursos de Pósgraduação e Graduação em Administração e Engenharia da Produção.

Palavras-chave: Setor metal mecânico. Gestão ambiental. Responsabilidade Social. Caso de Ensino.

\begin{abstract}
The mechanical engineering sector is a major environmental impactful, as well as consuming natural resources, generates a series of environmental pollutants . It is highlighted that is increasingly evident environmental and social issues, both in Brazil and in most Western countries. Environmental strategies proposes that new technologies are developed and actions on environmental, ecological and social economy. The Awning Metalmecânica Ltda is a company that has emerged because of the skills and entrepreneurial vision of the owner Rui Awning. After 33 years working in the domestic market the business needed to embrace new markets, it was becoming impossible to compete in the local market and the company had environmental problems. In this direction the company should adapt as quickly as possible, because the pressure from stakeholders influenced the marketing of products. The aim of this
\end{abstract}


teaching case is to propose reflections on the decisions and actions related to environmental management and social responsibility applied to companies Metalworking. Its use is indicated for Undergraduate and Graduate in Management and Production Engineering

Keywords: metal mechanic sector, environmental management, social responsibility, teaching case.

\section{Introdução}

A origem do Arranjo Produtivo Local Metalmecânico Automotivo (APLMMA) da Serra Gaúcha pode ser descrita a partir da história da região, basicamente povoada por imigrantes italianos no final do século XIX. Destaca-se que nos anos 50 a indústria de Caxias do Sul foi beneficiada intensamente pelo Programa de Metas do governo Juscelino Kubitschek, que projetava o desenvolvimento econômico por meio da modernização da sociedade brasileira, pela criação da indústria de base, especialmente automobilística, elétrica e indústria pesada. No período de 1957 a 1961, a produção industrial teve um crescimento real a cerca de 7\% ao ano, com porcentagens mais altas registradas pelas indústrias mecânicas (125\%), elétricas e de comunicações (380\%) e de equipamentos de transporte (600\%) (PATIAS, 2008).

O APLMMA da Serra gaúcha tem sua origem na vocação da região no setor de autopeças, motivada principalmente por grandes empresas do setor. As demandas dessas empresas fizeram com que surgissem inúmeras pequenas e médias empresas que prosperaram, fornecendo peças e serviços para estas e, consequentemente, para empresas do estado, do País e até para o Exterior (PATIAS, et al. 2009).

Atualmente, o APLMMA da Serra Gaúcha é o segundo maior Polo Metalmecânico do Brasil, devido ao grande número de empresas no segmento de peças, máquinas agrícolas e de veículos de grande porte, onde a cidade de Caxias do Sul sedia o maior número de empresas (SEVERO, et al., 2012). O APLMMA tem sua abrangência que compreende 17 municípios na Serra Gaúcha, que formam a base territorial do Sindicato das Indústrias Metalúrgicas, Mecânicas e de Material Elétrico de Caxias do Sul (SIMECS). São eles: Carlos Barbosa, Caxias do Sul, Cotiporã, Fagundes Varela, Farroupilha, Flores da Cunha, Garibaldi, Guabiju, Nova Pádua, Nova Prata, Nova Roma do Sul, Protásio Alves, São Jorge, São Marcos, Veranópolis, Vila Flores e Vista Alegre do Prata.

O APLMMA da Serra Gaúcha concentra certa de 2.588 empresas, onde grande parte é de micro e pequeno porte (95\%), gerando cerca de 62.775 postos de trabalho, visto que a cidade de Caxias do Sul representa aproximadamente $60 \%$ do Valor Adicionado Bruto (VAB) (SEVERO, et al., 2012).

Entretanto, conforme a Política Nacional do Meio Ambiente (BRASIL, PNMA, 2000) o setor metalmecânico enquadra-se na categoria de Indústria Metalúrgica, com classificação " $A$ " para atividades potencialmente poluidoras e, "Alto" para usuários de recursos naturais. Coerentemente, o setor Metalmecânico se caracteriza como "AAlto", ou seja, grande impactante ambiental, pois além de consumir recursos naturais, gera uma série de poluentes ambientais.

Destaca-se que está cada vez mais evidente a questão ambiental e social, tanto no Brasil como na grande maioria dos países do ocidente. A dimensão ambiental assumiu uma importância significativa para grande parte das empresas. As dimensões econômicas e mercadológicas da questão ambiental passaram a ser imprescindível na gestão organizacional. Consoante isso, as estratégias ambientais propõe que novas tecnologias e ações sejam desenvolvidas no âmbito da economia ambiental, ecológica e social, no intuito de evitar que elas se tornem parte do 
problema da insustentabilidade (NORGAARD, 2002; AMALADOSS; MANOHAR, 2013).

Neste contexto, emerge também as ações de responsabilidade social, que visam desenvolver parcerias, contribuir para a conscientização dos clientes, facilitar a obtenção de certificações, ser proativa frente às ações governamentais, melhorar a imagem pública e motivar a integração entre o público interno da organização, propiciando melhorias de competitividade à empresa (PORTER; KRAMER, 1999).

A Toldo Metalmecânica Ltda é uma empresa que surgiu em virtude das habilidades e visão empreendedora do proprietário Rui Toldo. Após 33 anos atuando no mercado nacional o empresário começou a sentir o desafio de continuar competindo, necessitava abarcar novos mercados, pois estava se tornando impossível competir no mercado local. Neste sentido, a Toldo buscou uma parceria com a Alpha para entrar em novos mercados, entretanto a empresa não estava preparada, necessita de uma série de ações de cunho ambiental e social para formalizar a parceria. A empresa deveria arcar com a multa ambiental de $R \$ 100.000,00$ que fora aplicada por não tratar adequadamente os resíduos gerados. A Toldo lançava a borra (resíduo de aço) e óleo refrigerante com água diretamente no Arroio Tega, principal regato de Caxias do Sul no Rio das Antas. Coerentemente, a empresa deveria se adequar o mais rápido possível, pois a pressão dos stakeholders influenciava a comercialização dos produtos, assim como a formalização da parceria com a Alpha para adentrar novos mercado.

\section{A Toldo Metalmecânica Ltda}

Rui Toldo, ainda na adolescência, trabalhava com a família em um pequeno vinhedo na Serra Gaúcha, o qual cultivava para a produção vinho em pequena escala. 0 pai de Rui, Alcides, sabia que a vida no campo traria poucas chances de conforto aos seus três filhos, pois o sítio onde viviam era pequeno, o qual permitia uma renda apenas para a subsistência. Para mudar de vida, aos 16 anos, Rui e seus irmãos foram estudar e trabalhar na cidade de Caxias do Sul. Durante o dia, Rui trabalhava como empacotador em um supermercado e a noite cursa o Ensino médio em uma escola pública da cidade. Em meados dos anos 70 Rui se formou como torneiro mecânico pelo Serviço Nacional de Aprendizagem Industrial (SENAI). Neste período, já com 20 anos de idade, Rui conseguiu um emprego em uma empresa de tornearia que prestava serviço para o setor agrícola.

De segunda a sexta-feira, e muitas vezes nos sábados, Rui trabalhava na tornearia, mas quando tinha folga voltava ao sítio para ajudar os seus pais no cultivo de uva, já que o trabalho rural era muito pesado. Nos 6 anos que trabalhou na tornearia Rui adquiriu o now how necessário para o exercício da profissão. Imbuído do espírito empreendedor, em 1979, mesmo com a crise do petróleo, Rui agora com 26 anos, resolve usar o dinheiro que havia economizado durante a época de trabalho, na compra de um torno e uma furadeira de bancada, para iniciar a empresa Toldo Metalmecânica Ltda, pois vislumbrava um futuro promissor na prestação de serviços de usinagem para componentes da indústria agrícola e para máquinas usadas na construção civil, já que estas áreas cresciam muito no Brasil.

O início dos anos 80 não foi fácil para o empreendimento de Rui, pois havia uma constante oscilação dos preços do petróleo, agravada pela crise inflacionária no Brasil, a qual iniciou a década de 80 com 54,9\% a.a. e em 1989 já estava com 1157,6\% a.a. Esta situação econômica induziu a redução no consumo interno, o que obrigou Rui a diversificar a produção, buscando serviços nos mais variados seguimentos e iniciando a produção de pequenos dispositivos e conjuntos soldados para montadoras de ônibus. Estas inovações de produto garantiram o emprego de seus funcionários, já que o valor das pessoas sempre foi um princípio e um recurso fundamental para o Rui. 
Em 1983 Rui casou-se com Helena, uma colega de aula que conheceu na Faculdade. Rui cursava Bacharelado em Administração de Empresas, e Helena cursava Bacharelado em Administração com ênfase no Comércio Internacional. Os cursos tinham algumas disciplinas afins, assim enquanto estudavam se conheciam, fluindo um amor e respeito mútuo. Helena auxiliava nos planos da empresa, que nesta época já possuía 9 tornos automáticos e 3 furadeiras de bancada. Em 1990 Rui resolve entrar no seguimento automotivo, especificamente peças para caminhões e ônibus, embora tivesse conhecimento, lhe faltava capital para investir. Para tanto, Rui buscou uma um financiamento junto a um Banco de Desenvolvimento, o qual forneceu o capital necessário para que a Toldo desenvolvesse novos produtos para o segmento automotivo.

Com o desenvolvimento de novos produtos, tais como: dispositivos hidráulicos para ônibus e elevadores de cargas acoplados a caminhões, a Toldo abarcou um novo segmento de mercado e tornando-se mais competitiva. Em apenas 3 anos a empresa duplicou a quantidade de funcionários e máquinas, empregando cerca de 120 pessoas em 1993.

0 ano de 1994 marcou a vida de Rui e Helena, pois nasce o filho tão desejado, que teve o nome do avô, Alcides. Outra boa notícia veio da economia, o governo federal, desenvolve o Plano Real, permitindo que em agosto deste ano a inflação no Brasil atingisse a marca histórica de 3\% a.m., permitindo uma estabilidade econômica no País, o que atraiu novos investidores e incentivou as exportações, pois havia uma paridade entre a moeda brasileira (Real) e o dólar Americano. Com a aliança estratégica estabelecida e com a situação econômica estável, a indústria automotiva brasileira iniciou um vertiginoso crescimento, pois a população valorizava sua moeda e consumia em grande escala.

A partir do ano 2000 a Toldo cresceu e modernizou seu parque fabril, adquirindo tornos e centros de usinagem de alta tecnologia. Coerentemente, iniciou-se um projeto de melhoria da qualidade com base nos grupos denominados Círculo de Controle da Qualidade (CCQ), que trabalhavam na melhoria dos processos e no ambiente de trabalho, respeitando o princípio de valorização do ser humano. Em 2007 a Toldo contava com 160 funcionários, entretanto a empresa enfrentava a crise Imobiliária dos Estados Unidos da América, a qual iniciava em agosto de 2007 e teve seus efeitos globais até o final de 2008.

Esta crise no Brasil provocou uma retração na economia, entretanto a agricultura e o setor de máquinas para construção civil conseguiu resistir às pressões de descapitalização mundial, o que permitiu que a Toldo conseguisse se sustentar no mercado, inclusive houve em 2008 um acordo inédito entre funcionários, através do Sindicato e empresas, com o acompanhamento do Ministério do Trabalho, que permitiu a redução temporária das horas de trabalho. Este acordo ficou conhecido com Flexibilização da Jornada de Trabalho, onde reduziu-se 5 dias por mês, descontados apenas $50 \%$ destes dias dos trabalhadores, em um prazo máximo de 3 mês. Este empenho conjunto de trabalhadores e empresas garantiu a manutenção dos empregos na Toldo, assim com de milhares de empregos na região nordeste do Rio Grande do Sul.

\section{Conhecendo a toldo atualmente}

Em 2012 a Toldo possuía um parque fabril de aproximadamente $9 \mathrm{mil} \mathrm{m}^{2}$, contava com aproximadamente 180 funcionários que atuavam em dois turnos de trabalho. 0 organograma da Toldo está representado na Figura 1. Os principais produtos desenvolvidos pela empresa eram os dispositivos hidráulicos para ônibus e os elevadores de cargas acoplados a caminhões. 


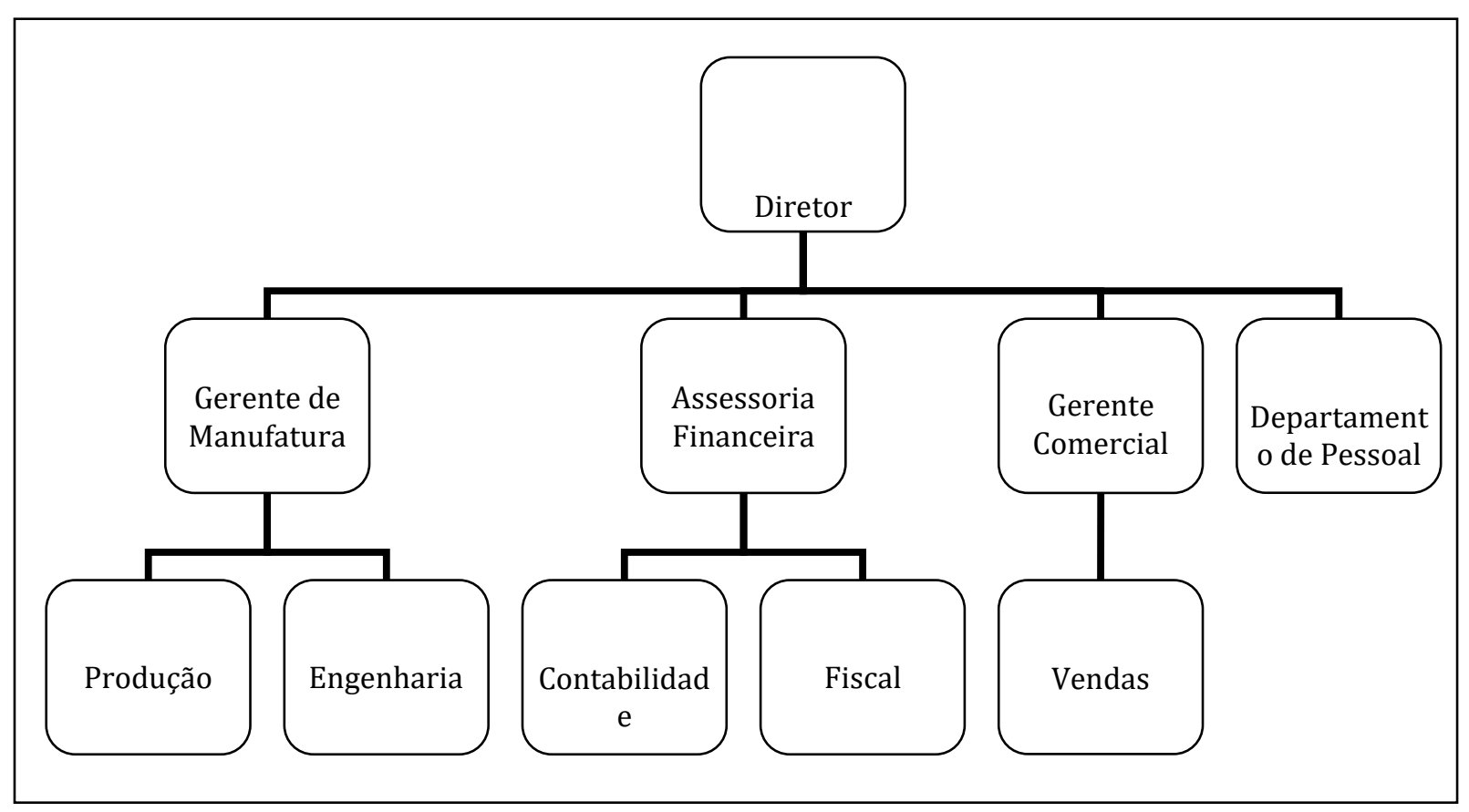

Figura 1 - Organograma da Toldo Metalmecânica Ltda

Fonte: Elaborado pelos autores (2013).

Passadas as dificuldades de ajustes do mercado, nos anos de 2009 a 2012 Rui iniciou um projeto de implantação de uma inovação organizacional, desenvolvido com o auxilio de uma consultoria especializada, tratava-se de um sistema de produção com base o Sistema Toyota de Produção e o Sistema Hyundai de Produção, o qual definia suas linhas de estratégia de operações.

Com a implantação do novo sistema de produção a Toldo melhorou os índices de qualidade e produtividade, passando de uma eficiência das horas trabalhadas de 63\% para 87\%. Para isto houve uma mudança cultural na organização, a começar pelo próprio Rui que teve que delegar aos gestores de produção e vendas maior autonomia. Além do compromisso do Rui com o novo sistema de produção, o trabalho em equipe foi um fator preponderante, sem o comprometimento dos gestores intermediários e dos operadores não é possível uma mudança rápida e eficaz. Nesta forma de trabalho a equipe se envolve nas decisões de qualidade, planejamento de produção e melhoria dos processos, pois parte do resultado da empresa era dividido com os trabalhadores, através de um programa de distribuição de lucros e resultados.

Contudo, Rui estava passando por problemas financeiros, conforme a Tabela 1. A empresa deveria arcar com a multa ambiental de $\mathrm{R} \$ 100.000,00$ que fora aplicada por não tratar adequadamente os resíduos gerados. A Toldo lançava a borra (resíduo de aço) e óleo refrigerante com água diretamente no Arroio Tega, principal regato de Caxias do Sul no Rio das Antas. Em virtude do descarte inadequado, o Arroio Tega possui intensa quantidade de metais pesados que impacta diretamente a fauna e flora da região. No que tange a quantidade de resíduos descartados inadequadamente, a média mensal era de $1830 \mathrm{~kg}$ de borra e 1130 litros de óleo refrigerante com água dispostos no meio ambiente. Neste cenário, a empresa deveria se adequar o mais rápido possível, pois a pressão dos stakeholders influenciava a comercialização dos produtos. 
Para tanto, Rui necessitava uma solução para superar a crise, e aspirava expandir a empresa, torando-a mais competitiva, abarcando novos mercados e divulgando seus produtos a nível mundial, já que detinha a patente destes.

\section{O novo cenário}

No início de 2013 Rui recebeu um convite da empresa Alpha para desenvolver uma nova parceria que permitiria a produção e comercialização de seus produtos nos Estados Unidos, Ásia e Europa, ampliando assim a sua participação de mercado e ampliação do faturamento. A Alpha oferecia um aporte de capital equivalente a 40\% do valor da Toldo, desta forma Rui ainda seria o acionista majoritário e as possibilidades de vendas para as montadoras levariam a Toldo para uma empresa exportadora e de classe mundial. 0 especial interesse da Alpha residia na tecnologia dos dispositivos hidráulicos para ônibus e elevadores de cargas acoplados a caminhões, os quais a Toldo detinha as patentes, assim a Alpha ganharia com o faturamento destes produtos atendendo os mercados mundiais onde atua.

Economicamente e tecnologicamente as duas empresas teriam todos os elementos favoráveis à efetiva aliança, entretanto a Alpha tinha uma exigência específica, que obrigava a Toldo a desenvolver um programa Sustentabilidade Ambiental e de Responsabilidade Social, inclusive necessitava apresentar o mais rápido possível um conjunto de planos de ação que levariam a implantação dos programas e a certificação IS014001. Esta não é uma tarefa fácil, pois demandaria um mapeamento da situação atual, estudo de oportunidades de melhorias, escolha de métodos que contribuem para a Gestão Ambiental (GA) e Responsabilidade Social Empresarial (RSE), alterando completamente o planejamento estratégico da Toldo. Neste sentido, Rui teria que implementar a curto prazo práticas de gestão ambiental que levassem a certificação ISO 14001, utilizando componentes menos poluentes, gerando menos resíduos nos processos de produção, assim como a empresa necessitava desenvolver projetos sociais para a comunidade na qual estava inserida.

Esta nova forma de gerir o negócio, com estratégias de GA e RSE, implicariam em uma alteração na cultura organizacional, que para tanto seria necessário desenvolver competências específicas nos gestores da Toldo, assim como Rui novamente teria que contar com o trabalho em equipe. Os custos tangíveis e intangíveis dessa mudança devem ser mensurados na decisão, pois não é apenas uma questão moral, mas de sobrevivência da própria organização, que tem a responsabilidade social de manter os empregos gerados.

Rui fazia vários questionamentos em uma reunião com o gerente de manufatura, o gerente comercial, a assessoria financeira e a coordenadora do departamento de pessoal - Será que a empresa tem agilidade suficiente para realizar as mudanças exigidas pela Alpha neste curto prazo? Será que estas ações ocasionam benefícios financeiros e socioambientais para a Toldo?

O dilema enfrentado por Rui, no que tange o crescimento ou manutenção do tamanho da empresa, deverá ser resolvido com competência e serenidade, mas com agilidade, pois a decisão deverá ocorrer o mais breve possível, já que a Toldo deve atender a Legislação Ambiental e encontra-se com sérios problemas financeiros, assim como a Alpha estipulou uma semana para a resposta, e três meses para a apresentação dos planos de ação para os programas de Sustentabilidade Ambiental e Responsabilidade Social. 


\begin{tabular}{l|r}
\hline \multicolumn{2}{c}{ Balanço Financeiro - 2012 (em R\$) } \\
\hline \multicolumn{1}{c|}{ Discriminação } & \multicolumn{1}{c}{ Valor } \\
\hline Saldo do exercício anterior & $309.600,32$ \\
\hline Recursos recebidos no exercício & $15.830 .412,05$ \\
\hline Despesas no exercício & $16.057 .966,82$ \\
\hline Disponibilidade final em 31.12.2012 & $82.045,55$ \\
\hline
\end{tabular}

Tabela 1: Resumo do Balanço financeiro da Toldo Metalmecânica Ltda

Fonte: Elaborado pelos autores (2013).

\section{As possibilidades}

Ciente do problema, o empresário necessitava tomar uma ação o mais breve possível. Após reunir-se com a sua equipe de gestão, percebeu que se permanecesse atuando no mercado nacional teria que aumentar a sua produção, pois a reserva financeira do exercício de 2012 não era suficiente para quitar a multa ambiental da empresa. Contudo a sua capacidade de atuação no mercado interno estava limitada, sem chances de expansão.

Uma possibilidade identificada para a empresa era formalizar a parceria com a Alpha, que entraria com o aporte de $40 \%$ do Valor de Mercado da Toldo. Neste contexto, a empresa adentraria novos mercados, tais como os Estados Unidos, Ásia e Europa e ampliaria o seu faturamento, assim como a sua marca seria globalizada. Entretanto, a empresa deveria desenvolver um plano de ações ambientais visando posteriormente a obtenção da ISO 14001, assim como projetos de cunho social para a comunidade na qual estava inserido. Vale ressaltar que o custo de disposição final adequada por $\mathrm{Kg} /$ borra é de aproximadamente $\mathrm{R} \$ 6,50$, já o tratamento adequado por litro/óleo refrigerante com água é em média de $\mathrm{R} \$ 21,00$. Neste contexto, seria viável a implementação de uma área responsável pela sustentabilidade ambiental e as ações sociais, que primasse para a divulgação das práticas e ações no âmbito do marketing ambiental. Contudo, Rui necessitava organizar a empresa o mais rápido possível, pois o seu tempo era extremamente curto.

Outra possibilidade vista por Rui seria competir no mercado nacional, desenvolvendo um produto inovador. Para tanto, seria necessário investigar o ambiente de mercado a fim de conhecer as tendências e antecipar as oportunidades, e com base nas necessidades do mercado desenvolver um novo produto. 0 empresário também poderia utilizar uma estratégia de marketing através de comunicação rápida entre as vendas e com flexibilidade em relação à entrega dos produtos aos clientes. Entretanto, essa inovação poderia levar algum tempo, e Rui tinha receio que não suportaria financeiramente a espera. Todas as ações propostas ocasionavam dúvidas, e Rui necessita decidir pela melhor opção o mais rápido possível.

\section{Notas de ensino}

\section{Utilização Recomendada}

O caso foi elaborado a partir da perspectiva do estudo das competências organizacionais, o qual poderá ser aplicado em cursos de Graduação e Pós-Graduação em administração e Engenharia da Produção, nas disciplinas de sustentabilidade, gestão ambiental, responsabilidade social, marketing sustentável, gestão socioambiental, gestão da produção e inovação. Destaca-se que 
este caso poderá ser aplicado sobre outras perspectivas como, por exemplo, o Desenvolvimento Sustentável e a Competitividade das Organizações. Neste sentido, será importante ajustar os questionamentos a respeito do texto e possibilidades de solução do problema.

O professor que aplicar o caso de ensino poderá utilizar o referencial teórico contido no capítulo Possibilidade para Análise do Caso, o qual disponibiliza elementos da literatura para fundamentar as decisões dos estudantes.

\section{Objetivos de Aprendizagem}

Com a análise do caso de ensino será possível abordar e refletir vários temas de aprendizagem. Entre eles:

a) competências e habilidades necessárias ao gestor no século XXI;

b) decisões relacionadas ao porte da empresa, discutindo a posição da organização no setor em que atua;

c) decisões e ações associadas à gestão ambiental e a responsabilidade social aplicada às empresas Metalmecânicas;

d) as dificuldades das organizações perante as novas exigências de mercado globalizado tendo que se adaptar a elas;

e) estratégias de inovações no que tange o contexto da Indústria Metalmecânica.

\section{Sugestões de Questionamentos para Discussão em Sala de Aula}

1) Quais as competências e habilidades deve ter um gestor, para que seja possível a percepção das questões sociais e ambientais no âmbito das organizações?

2) Perante a importância das ações sociais no contexto organizacional, como a empresa poderia estruturar no planejamento estratégico as ações sociais? Quais seriam os projetos sociais mais indicados?

3) No caso de ensino descrito, quais as práticas ambientais que poderiam primar para a sustentabilidade ambiental da empresa, em busca da certificação ISO 14001? Como elas seriam estruturadas?

4) Schumpeter (1934) e Damanpour (1991) descrevem algumas formas de inovação, qual delas está atuando no caso descrito? Fundamente a sua resposta.

5) O manual de Oslo (2005) menciona diferentes tipologias de inovação, qual dessas tipologias poderia ter maior êxito para solucionar a situação problema?

6) Caso você fosse o personagem Rui, referido no caso, perante a situação descrita, que ação estratégica você tomaria, e por quê?

\section{Plano de Classe Sugerido}

Recomenda-se que os temas de gestão ambiental e responsabilidade social sejam previamente discutidos em aula. 0 momento indicado para a utilização deste caso de ensino em um curso de graduação e pós-graduação em administração é em seu ponto intermediário/final, para tanto os alunos necessitarão tomar decisões estratégicas a partir dos conceitos abordados em aula. 
Sugere-se a estrutura a seguir (3 horas de duração):

\begin{tabular}{|l|c|}
\hline $\begin{array}{l}\text { Apresentação do caso de ensino e das temáticas } \\
\text { discutidas }\end{array}$ & 1h30min \\
\hline $\begin{array}{l}\text { Discussão do caso de ensino em grupos de no máximo 5 } \\
\text { alunos }\end{array}$ & $30 \mathrm{~min}$ \\
\hline Discussão do caso de ensino em plenária & $1 \mathrm{~h}$ \\
\hline
\end{tabular}

\section{Possibilidades para análise do caso}

\section{Responsabilidade Social}

A Responsabilidade Social vem sendo constantemente discutida no meio empresarial, pois muitas organizações têm se utilizado desta prática, por meio de diversos programas na área social, procurando demonstrar principalmente sua função social perante a comunidade na qual está inserida (AMALADOSS; MANOHAR, 2013). Gerar lucros para os acionistas deixou de ser a única preocupação das empresas. Preocupações sociais, legais e éticas adentraram nas empresas, que passaram por um período de transição no modo de pensar suas estratégias e sua missão perante a sociedade (ASHLEY, 2005).

Ao utilizar arcabouços norteadores das principais decisões empresariais, na análise das políticas de responsabilidade social, a empresa descobre que estas práticas podem ser muitos mais do que um custo ou entrave, tornando-se fonte de oportunidades, inovação e vantagem competitiva (PORTER; KRAMER, 2006).

A nível mundial as organizações contam com a Global Reporting Initiative (GRI) que trata-se de uma organização baseada em rede, pioneira no quadro de relatórios de sustentabilidade. A estrutura de relatório de sustentabilidade estabelece os princípios e indicadores de desempenho que as empresas podem usar para medir, relatar e divulgar contas aos stakeholders, buscando descrever os impactos a nível econômico, ambiental e social, (GRI, 2012). Os indicadores de desempenho social da GRI identificam aspectos de desempenho fundamentais referentes a práticas trabalhistas, direitos humanos, sociedade e responsabilidade pelo produto (GRI, 2012).

No Brasil, as organizações contam também com o Instituto Ethos de Empresas e Responsabilidade Social (ETHOS, 2013), criada com a missão de sensibilizar, mobilizar e auxiliar as empresas a gerir seus negócios de forma socialmente responsável. Os indicadores de responsabilidade social empresarial (RSE) preconizados pelo Instituto Ethos (2013) elencam sete grandes temas: i) valores, transparência e governança; ii) público interno; iii) meio ambiente; iv) fornecedores; v) consumidores e clientes; vi) comunidade; vii) governo e sociedade. 0 gestor poderia elencar os indicadores de RSE que mais de se enquadram para atender o seu problema, e assim iniciar uma implementação com planos de avaliação a médio e longo prazo.

\section{Gestão Ambiental}

A consciência empresarial a respeito dos problemas ambientais começaram a ter maior relevância após os fatores relacionados a explosão populacional, a industrialização e a urbanização exagerada. Nas últimas décadas houve mudanças na maneira como as empresas passaram a ver a questão ambiental associada ao seu processo produtivo. As organizações modificaram a sua forma de atuação para, no mínimo, reduzir os impactos ambientais adversos 
(YORK; ROSA; DIETZ, 2003). A sustentabilidade ambiental vem assumindo importância crescente a partir da década de 90 por duas razões: i) pela dimensão e abrangência; e, ii) pela consciência dos stakeholders ao impacto ambiental causado pela atividade industrial (SADLER, 1996; JÄNICKE, 2008).

A concepção que existia entre a maioria dos empresários, até poucos anos atrás, de que a adoção de uma gestão ambiental eficiente colidia com a manutenção de percentuais de lucros competitivos foi aos poucos sendo ultrapassada (SEVERO, et al., 2012). A responsabilidade socioambiental passa a ser vista como uma necessidade de sobrevivência, levando empresas à adoção de uma estratégia diferente da anterior, que até então se resumiam à questão econômica, como competitividade, eficiência, lucratividade, marcada agora por um comportamento ético-ambiental.

Para González-Benito e González-Benito (2006) o tamanho, mensurado pelo número de empregados ativos, é uma das variáveis estruturais que mais influencia nas ações ambientais das empresas. Ainda para os autores, nas grandes empresas a gestão de negócios se torne indivisível da gestão ambiental, requerendo investimentos em tecnologia, recursos humanos ou certificações, assim como os esforços ambientais das grandes empresas têm um impacto positivo sobre um grande número de clientes.

Devido à degradação ambiental que vem ocorrendo e a pressão governamental exercida nas organizações, para que as mesmas adotem uma postura ambientalmente correta, direcionada à preservação ambiental, os cuidados com o meio ambiente vem aumentando na mesma proporção que o interesse da contabilidade para este assunto (DEEGAN, 2002; MATHEWS, 1997). A literatura aponta para a performance positiva das empresas que investem na de se prevenção da emissão de resíduos e tecnologias para controle da poluição (KING; LENOX, 2002; DORION et al., 2012).

Como forma de estudar a sustentabilidade, Elkington (1999) apresenta o Triple Bottom Line (tripé da sustentabilidade) que representa a sobreposição e integração de três pilares, o desenvolvimento econômico, a responsabilidade social e a gestão ambiental, como direcionadores do desenvolvimento sustentável, seguindo os temas People, Planet and Profi (pessoas, planeta e lucro). Barbieri et al. (2010) complementa a discussão, ao apresentar as três dimensões da sustentabilidade: i) dimensão social - preocupação com os impactos sociais das inovações nas comunidades humanas dentro e fora da organização (desemprego; exclusão social; pobreza; diversidade organizacional, entre outros); ii) dimensão ambiental preocupação com os impactos ambientais pelo uso de recursos naturais e pelas emissões de poluentes; iii) dimensão econômica - preocupação com a eficiência econômica, sem a qual elas não se perpetuariam.

Os benefícios de desenvolvimento das atividades empresariais sustentáveis emergem no campo de vantagem competitiva, como um veículo para melhorar a eficiência dos recursos, reduzindo o desperdício, abrindo novos mercados e impulsionando a capacidade de conhecimento que pode estar na vanguarda da construção de uma crise pós-sustentável da economia financeira (POTTS, 2010).

No entanto, as escolhas estratégicas que as empresas conduzem em relação à gestão ambiental relacionam-se com a interpretação que seus gestores têm do ambiente, bem como esse ambiente influencia essas decisões, como uma oportunidade ou ameaça, como benefício ou como custo. Consoante isso, as técnicas de prevenção da poluição, integram as práticas de gestão ambiental em sistemas de gestão tradicionais. Neste contexto, as empresas podem minimizar os impactos negativos fazendo o uso de diversas práticas, tais como: Sistema de Gestão de Resíduos (SGR), Estação de Tratamento de Efluentes (ETE), Certificação ISO 14001, 
Análise do Ciclo de Vida (ACV), Produção mais Limpa (P+L), Reciclagem, Simbiose Industrial (SI), entre outras.

\section{Inovação}

Decisões e ações associadas à inovação poderiam ser tomadas pelo protagonista. A inovação permite às regiões menos favorecidas avançar, como as mais desenvolvidas, não só através da imitação dos resultados por estas já alcançadas, mas também pelo trabalho feito de acordo com as suas próprias características e exigências, para poder adaptar-se às condições de competitividade numa economia global (PATIAS, et al., 2009).

Para Schumpeter (1934) e Damanpour (1991) A inovação está relacionada com a adoção de um novo método de produção, de um novo produto (mercadorias, serviços), de uma nova forma de organização ou a conquista de um novo mercado, ou ainda a inovação também pode ser uma nova estrutura, um novo sistema administrativo, um novo processo tecnológico de produção.

O Manual de Oslo (2005) classifica a inovação em quatro tipos distintos: i) inovação de produto: trata-se da introdução de um produto (bem ou serviço) novo ou significativamente melhorado; ii) inovação de processo: processo novo ou substancialmente aprimorado, como também equipamentos novos ou significativamente aperfeiçoados em atividades de suporte à produção; iii) inovação em marketing: ocorre pela implementação de um novo método de marketing com mudanças significativas na concepção do produto ou em sua embalagem, no posicionamento do produto, em sua promoção ou na fixação de preços; iv) inovação organizacional: consiste na implementação de um novo método organizacional nas práticas de negócio da empresa, na organização do seu local de trabalho.

Analisando estas diferentes tipologias de inovação o gestor poderia identificar a que melhor se enquadra no contexto de sua empresa. E, dessa maneira, tomar a decisão mais adequada com relação a inovação, considerando ainda outros aspectos, como o ambiente da organização, pois o ambiente inovador, segundo Simantob e Lippi, (2003) e Dorion et al. (2010) é composto por pessoas qualificadas e treinadas continuamente, comunicação aberta e transparente, sem filtros, ambiente propício a troca de informações e à ousadia e premiação sempre voltada para o reconhecimento coletivo. Neste sentido as organizações devem criar ambientes de suporte, o que significa criar e sustentar o ambiente organizacional, estruturar a organização para permitir ideias no ambiente de trabalho e clarificar o foco estratégico da organização para que as ideias inovativas sejam passíveis de implementação.

Outra forma de ver a inovação, está na proposição de Gallouj e Weinstein (1997), que classificada em modos e modelos: i) Inovação radical, onde o produto é totalmente novo; ii) inovação baseada na melhoria, com melhoria de características, sem alterar a arquitetura e/ou sistema; iii) inovação incremental, quando ocorre a substituição ou adição de características. iv) inovação ad hoc, que trata da solução para um problema particular de um cliente; v) inovação recombinativa, a qual é oriunda da combinação de características existentes; vi) inovação formalizada que é expressa pela padronização, especificação, formalização das recombinações.

\section{Obtenção dos Dados}

Os dados foram coletados a partir de entrevista semiestruturada em profundidade realizada com o gestor responsável pela administração da empresa. Posteriormente a coleta dos dados, realizou-se a transcrição e interpretação da entrevista, onde se buscou aliar juntamente com a história real elementos fictícios para chamar a atenção do leitor ao conflito existente, assim a história ter um cunho acadêmico. Para tanto, o nome da empresa e do proprietário são fictícios 
para preservar o caso real.

\section{Referências}

AMALADOSS, M. X.; MANOHAR, H. L. Communicating corporate social responsibility - a case of CSR Communication in emerging economies corporate. Social Responsibility and Environmental Management, v. 20, n. 2, p. 65-80, 2013.

ASHLEY, P. Ética e responsabilidade social nos negócios. 2. ed. São Paulo: Saraiva, 2005. 340p.

BARBIERI, J. C.; VASCONCELOS, I. F. G.; ANDREASSI, T.; VASCONCELOS, F.V. Inovação e sustentabilidade: modelos e proposições. RAE, v.50, n.2, p.146-154, abr/jun 2010.

BRASIL. PNMA - POLÍTICA NACIONAL DE MEIO AMBIENTE. Lei no 10.165 de 27 de dezembro de 2000. Altera a Lei no 6.938, de 31 de agosto de 1981, que dispõe sobre a Política Nacional do Meio Ambiente, seus fins e mecanismos de formulação e aplicação, e dá outras providências. Brasília - DF, 27 de dezembro de 2000. Disponível em: <. https://www.planalto.gov.br/ccivil_03/Leis/L10165.htm>. Acesso em: 10 fev. 2012.

DAMANPOUR, F. (1991). Organizational innovation: a meta-analysis of effects of determinants and moderators. Academy of Management Journal, v. 34, n. 3, p. 555-590.

DEEGAN, C. Introduction: the legitimizing effect of social and environmental disclosures - a theoretical foundation. Accounting, Auditing, and Accountability Journal, v. 15, n. 3, p. 282$311,2002$.

DORION, E.; CHALELA, L. R.; LAZZARI, F.; SEVERO, E. A.; GIULIANI, A. C. Profiles of entrepreneurship and innovation: debate on business incubators in Brazil. World Review of Entrepreneurship, Management and Sustainable Development, v. 6, p. 17-34, 2010.

DORION, E. ; SEVERO, E. A. ; OLEA, P. M. ; NODARI, C. H. ; GUIMARAES, J. C. F. . Hospital environmental and residues management: Brazilian experiences. Journal of Environmental Assessment Policy and Management, v. 14, p. 1-18, 2012.

ELKINGTON, J. Cannibals with forks. Canada: New Society, 1999.

GALlOUJ, F.; WEINSTEIN, O. Innovation in services. Research Policy. North-Holland. n. 26, p. 537-556, 1997.

GONZÁLEZ-BENITO, J. G.; GONZÁLEZ-BENITO, O. G. A review of determinant factors of environmental proactivity. Business Strategy and the Environment, v.15, p. 87-102, 2006.

GRI - GLOBAL REPORTING INITIATIVE. Indicator protocols set environment (EM), 2012. Disponível em: < https://www.globalreporting.org/resourcelibrary/G3.1-EnvironmentIndicator-Protocols.pdf > . Acesso em: 11 jul. 2012.

INSTITUTO ETHOS. Indicadores de responsabilidade socioambiental, 2013. Disponível em: <http://www3.ethos.org.br/wp-

content/uploads/2013/07/IndicadoresEthos_2013_PORT.pd/>. Acesso em: jul. 2013.

JÄNICKE, M. Ecological modernisation: new perspectives. Journal of Cleaner Production, v. 16, n. 5, p. 557-565, 2008.

KING, A. A.; LENOX, M. J. Exploring the locus of profitable pollution reduction, Management Science, v. 48, n. 2, p. 289-299, 2002.

MANUAL DE OSLO. The measurement of scientific and technological activities. 2005. 93p.

MATHEWS, M. Twenty-five years of social and environmental research: is there a silver jubilee 
to celebrate? Accounting, Auditing, \& Accountability Journal, v. 10, n. 4, p. 481-531, 1997.

NORGAARD, R. Valorização ambiental na busca de um futuro sustentável. In: CAVALCANTI, C. (Org.). Meio ambiente, desenvolvimento sustentável e políticas públicas. São Paulo: Cortez, 4. ed., 2002. p. 83-92.

PATIAS, T. Z. A governança no arranjo produtivo local metalmecânico da Serra Gaúcha. 2008, 110 p. Dissertação. (Mestrado em Administração) - Programa de Pós-Graduação Mestrado em Administração, Universidade de Caxias do Sul, Caxias do Sul, 2008.

PATIAS, T. Z.; SEVERO, E. A.; OLEA, P. M.; GALELLI, A. 0 arranjo produtivo local metalmecânico automotivo da Serra Gaúcha como um sistema de inovação. Revista de Administração da UNIMEP, v. 7, p. 01-20, 2009.

POTTS, T. The natural advantage of regions: linking sustainability, innovation, and regional development in Australia. Journal of Cleaner Production, v. 18, n. 8, p. 713-725, 2010.

PORTER, M. E.; KRAMER, M. R. Philanthropy's new agenda: creating value. Harvard Business Review, p.121-130, nov/dec. 1999.

SADLER, B. Environmental assessment in a changing world: evaluating practice to improve performance. Canadian: Environmental Assessment Agency/International Association for Impact Assessment, 1996

SCHUMPETER, J. A. The theory of economic development. Cambridge: Harvard University Press, 1934.

SEVERO, E. A.; DORION, E.; OLEA, P. M.; CAMARGO, M. E.; NODARI, C. H.; CRUZ, M. R. Cleaner production: cases of the metal-mechanic automotive cluster of Serra Gaúcha, Brazil. African Journal of Business Management, v. 6, p. 10232-10237, 2012.

SIMANTOB, M.; LIPPI, R. Guia valor econômico de inovação nas empresas. São Paulo: Globo, 2003.

YORK, R.; ROSA, E. A.; DIETZ, T. Footprints on the earth: the environmental consequences of modernity. American Sociological Review, v. 68, n. 2, p. 279-300, 2003. 